\title{
ANALISIS PENERIMAAN PENGGUNA LEARNING MANAGEMENT SYSTEM MENGGUNAKAN MODEL UTAUT
}

\author{
Benedika Ferdian Hutabarat ${ }^{1)}$ \\ ${ }^{1}$ Fakultas Sains dan Teknologi, Universitas Jambi \\ email: benedika@unja.ac.id
}

\begin{abstract}
E-learning is emerging as an important strategy for providing broad and easy access to high quality education. In Indonesia, the concept of e-learning is usually applied in universities to support learning activities and student administration. This study aims to analyze the factors that affect the level of satisfaction by adopting the UTAUT (Unified Theory of Acceptance and Use of Technology) model and seeing the effect of user satisfaction. by intending to continue to use a new technology (elearning). The UTAUT model was adopted in this study because it has a useful measurement tool for policy makers to assess the likelihood of the successful introduction of new technology. A quantitative research approach with a survey method is used to determine the factors that affect user satisfaction and the intention to use. The quantitative analysis of survey data was carried out using statistical techniques Partial Least Square Structural Equation Modeling (PLS-SEM) and utilizing SmartPLS 3.2.4 software. In this study, two factors were identified that affect user satisfaction, namely effort expectancy. Furthermore, user satisfaction affects intention to use.
\end{abstract}

Keywords: e-learning, UTAUT, user satisfaction, intention to use, PLS-SEM

\section{PENDAHULUAN}

Perkembangan dunia teknologi infomasi dan komunikasi (TIK) yang berkembang pesat menyebabkan media elektronik digunakan dalam penyebaran berbagai informasi. Dalam bidang pendidikan, perkembangan teknologi informasi memunculkan paradigma baru dalam proses pembelajaran dimana prosesnya tidak hanya sebatas kegiatan pembelajaran tatap muka di dalam kelas tetapi juga dapat dilakukan secara online (Hasanah et al., 2019). Sistem pembelajaran ini dikenal dengan pembelajaran elektronik (e-learning) (Ramayasa, 2015). E-learning memiliki sejumlah manfaat penting bagi siswa, termasuk akses ke alat dan sumber pembelajaran seperti teks, audio, video, diskusi online, dan hasil evaluasi. Ini adalah alat yang sangat berguna untuk meningkatkan kualitas pembelajaran (Mohamed Ali, 2016). Kehadiran e-learning tidak hanya meningkatkan kecepatan transfer pengetahuan, tetapi dalam metode ini, kegiatan belajar mengajar bergeser dari bentuk penyampaian yang berpusat pada pengajar ke bentuk pengiriman yang berpusat pada siswa. Elearning muncul sebagai strategi penting untuk memberikan akses yang luas dan mudah pada pendidikan berkualitas tinggi (Talebian et al.,
2014). Sejak tahun 2000, peran teknologi informasi dalam kegiatan pembelajaran untuk mendukung e-learning mulai diciptakan oleh perguruan tinggi. Di Indonesia, konsep $e$ learning biasanya diterapkan di perguruan tinggi untuk mendukung kegiatan pembelajaran dan administrasi kemahasiswaan (Lee et al., 2012), terlebih lagi saat dunia mengalami pandemi Covid-19, penggunaan $e$ learning untuk proses belajar tanpa pertemuan fisik semakin banyak digunakan. Universitas Jambi yang merupakan salah satu perguruan tinggi negeri di Indonesia pun turut menggunakan e-learning dalam proses belajar mengajar. E-learning yang digunakan berupa learning management system (LMS) berbasis Moodle. LMS tersebut dapat diakses melalui laman https://elearning.unja.ac.id dan aplikasi mobile. Permasalahan yang muncul adalah apakah siswa (dalam hal ini mahasiswa) sudah puas (satisfaction) dan berniat untuk menggunakan (intention to use).

Penelitian ini bertujuan untuk menganalisis faktor-faktor yang mempengaruhi tingkat kepuasan dengan mengadopsi model UTAUT (Unified Theory of Acceptance and Use of Technology) dan melihat pengaruh kepuasaan pengguna dengan berniat untuk terus menggunakan suatu 
teknologi baru (e-learning). Model UTAUT diadopsi pada penelitian ini dikarenakan memiliki alat pengukuran yang berguna bagi para pemangku kebijakan untuk menilai kemungkinan keberhasilan pengenalan teknologi baru (Sedana \& Wijaya, 2012). UTAUT pun telah banyak diimplementasikan di lingkungan akademik oleh banyak peneliti (Sedana \& Wijaya, 2012). UTAUT merupakan suatu model yang disusun berdasarkan modelmodel penerimaan teknologi sebelumnya seperti Theory of Reasoned Action (TRA), Theory of Planned Behaviour (TPB), TaskTechnology Fit Theory, dan terutama Technology Acceptance Model (TAM) (Venkatesh et al., 2003). UTAUT bertujuan untuk menjelaskan minat pengguna dalam menggunakan sistem informasi dan perilaku pengguna berikutnya. Teori ini berpendapat bahwa empat faktor utama (performance expectancy, effort expectancy, social influence, dan facilitating conditions) adalah penentu langsung niat penggunaan dan perilaku. Akan tetapi, pada penelitian yang dilakukan oleh Chan et al. (2010), keempat faktor (konstruk) tersebut diadopsi untuk menjadi pondasi awal untuk mengukur kepuasaan pengguna pada suatu kesuksesan sistem informasi yang baru (Chan et al., 2010). Selanjutnya, pada penelitian yang dilakukan oleh Cho \& Ngai (2014) terdapat hubungan antara kepuasaan pengguna (user satisfaction) dan niat pengguna (intention to use) (Cho \& Ngai, 2014).

Penelitian menggunakan enam konstruk yaitu performance expectancy (PE), effort expectancy (EE), social influence (SI), facilitating conditions (FC), user satisfaction (USE), dan intention to use (ITU) untuk melihat pengaruh antar faktor pada evaluasi $e$ learning. Performance expectancy dipahami sebagai sejauh mana pengguna yakin bahwa menggunakan suatu layanan akan menghasilkan manfaat bagi kinerja mereka. Effort expectancy didefinisikan sebagai tingkat kemudahan yang terkait dengan penggunaan suatu layanan. Social influence merupakan pertimbangan interpersonal untuk menggunakan teknologi. Facilitating conditions mewakili evaluasi pengguna terhadap lingkungan kerja ketika menggunakan suatu layanan. User satisfaction merupakan kepuasaan pengguna terhadap suatu layanan. Sedangkan intention to use merupakan niat pengguna untuk terus menggunakan suatu layanan. Model strultural penelitian ini dapat dilihat pada Gambar 1.

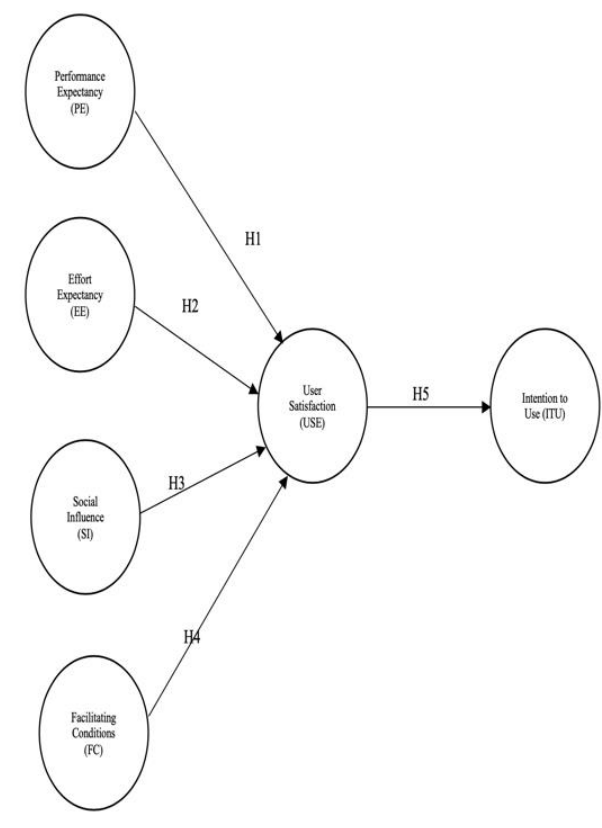

Gambar 1. Model Penelitian

\section{Hipotesis}

H1. Performance Expectancy berpengaruh positif dan signifikan terhadap User Satisfaction.

H2. Effort Expectancy berpengaruh positif dan signifikan terhadap User Satisfaction.

H3. Social Influence berpengaruh positif dan signifikan terhadap User Satisfaction.

H4. Facilitating Conditions berpengaruh positif dan signifikan terhadap User Satisfaction.

H5. User Satisfaction berpengaruh positif dan signifikan terhadap Intention to Use.

\section{METODOLOGI PENELITIAN}

\section{Pengumpulan Data dan Sampling}

Pengumpulan data dalam penelitian ini dilakukan dengan metode survei yaitu berupa kuesioner online dengan menggunakan Google Forms. Sampel penelitian diambil berdasarkan teknik purposive sampling. Sampel yang dibutuhkan dalam penelitian ini adalah mahasiswa Universitas Jambi yang menggunakan LMS Universitas Jambi di laman https://elearning.unja.ac.id. Calon responden adalah pengguna LMS Universitas 
Jambi yang aktif menggunakannya di periode Februari-Juni 2020. Kemudian secara manual mengirimkan link Google Forms dikirim ke calon responden melalui pesan langsung di whatsapp group mahasiswa. Pesan ini berisi pengenalan singkat, tujuan penelitian, permintaan pengisian kuisioner dan link ke Google Forms untuk bisa mengakses kuisioner.

\section{Metode Pengukuran}

Kuesioner dirancang untuk mengumpulkan informasi yang dibutuhkan dari responden untuk tujuan penelitian. Kuesioner terbagi menjadi tiga aspek utama yang telah dimodifikasi dari penelitian sebelumnya yaitu informasi tentang latar belakang responden, informasi tentang pengalaman responden dalam menggunakan LMS Universitas Jambi, dan informasi berdasarkan model penelitian. Untuk skala pengukuran angket dibuat pertanyaan dengan mengadopsi likert scale sebanyak 5 poin, yaitu 1 = Sangat Tidak Setuju, 2 = Tidak Setuju, 3 = Netral, 4 = Setuju, dan 5 = Sangat Setuju.

\section{Metode Analisa Data}

Kuesioner yang didapat selanjutnya diproses lebih lanjut. Data yang valid dari kuesioner tersebut diproses menggunakan SmartPLS 3. Model struktural dari penelitian ini dapat dilihat pada Gambar 2. Analisa data pada penelitian ini dilakukan dengan tiga tahap yaitu analis outer model, inner model, dan pengujian hipotesis.

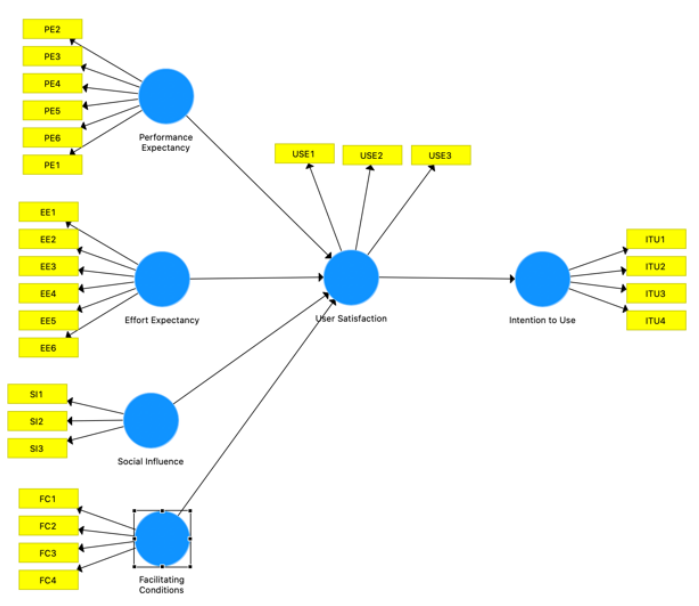

Gambar 2. Model Struktural

\section{HASIL DAN PEMBAHASAN}

\section{Profil Responden}

Jumlah responden yang mengisi kuisioner di Google Forms sebanyak 119 mahasiswa, namun hanya 100 kuisioner diproses lebih lanjut. Sebanyak 19 kuesioner ditolak karena tidak valid dan tidak memenuhi persyaratan. Misalnya, ada mahasiswa yang mengisi jawaban yang bertolak belakang maknanya ketika diberikan reverse question. Demografi singkat responden dapat dilihat pada Tabel 1.

Tabel 1. Profil Responden

\begin{tabular}{|l|l|l|l|}
\hline \multirow{2}{*}{ Demografi } & \multirow{2}{*}{ Kategori } & \multicolumn{2}{|c|}{ Responden } \\
\cline { 3 - 4 } $\begin{array}{l}\text { Jenis } \\
\text { Kelamin }\end{array}$ & Laki-Laki & 63 & 63 \\
\cline { 2 - 4 } & Perempuan & 37 & 37 \\
\hline \multirow{5}{*}{$\begin{array}{l}\text { Frekuensi } \\
\text { Akses }\end{array}$} & $\begin{array}{l}\text { Beberapa } \\
\text { kali dalam } \\
\text { sehari kali }\end{array}$ & 13 & 13 \\
\cline { 2 - 4 } $\begin{array}{l}\text { Universitas } \\
\text { Jambi }\end{array}$ & $\begin{array}{l}\text { 6-7 kalam } \\
\text { seminggu } \\
\text { dalam } \\
\text { seminggu }\end{array}$ & 13 & 5 \\
\cline { 2 - 4 } & $\begin{array}{l}\text { 1-5 kali } \\
\text { dalam } \\
\text { seminggu }\end{array}$ & 28 & 13 \\
\cline { 2 - 4 } & $\begin{array}{l}\text { Jarang atau } \\
\text { tidak setiap } \\
\text { minggu }\end{array}$ & 41 & 28 \\
\hline
\end{tabular}

\section{Analisis Outer Model}

Analisis outer model dilakukan untuk memastikan bahwa pengukuran yang dilakukan layak, valid, dan reliabel dengan menentukan hubungan antara variabel laten dengan indikatornya. Pada tahap ini kita mencari nilai validitas konvergen dan validitas diskriminan. Nilai validitas konvergen merupakan nilai loading factor pada variabel laten (konstruk) beserta indikatornya. Indikator dinyatakan valid konvergen jika nilai faktor pembebanan $(\lambda)>=$ 0,5 (Hasanah et al., 2019). Tabel 2 ditunjukkan bahwa model penelitian memiliki nilai loading 
factor untuk masing-masing indikator $>=0,5$. Oleh karena itu, langkah-langkah tersebut menunjukkan validitas konvergen yang memadai.

Tabel 2. Loading Factor

\begin{tabular}{|c|c|c|}
\hline Indikator & $\begin{array}{l}\text { Loading } \\
\text { Factor }\end{array}$ & Keterangan \\
\hline $\begin{array}{l}\text { Performance } \\
\text { Expectancy } 1 \text { (PE1) }\end{array}$ & 0,807 & Valid \\
\hline $\begin{array}{l}\text { Performance } \\
\text { Expectancy } 2 \text { (PE2) }\end{array}$ & 0,815 & Valid \\
\hline $\begin{array}{l}\text { Performance } \\
\text { Expectancy } 3 \text { (PE3) }\end{array}$ & 0,874 & Valid \\
\hline $\begin{array}{l}\text { Performance } \\
\text { Expectancy } 4 \text { (PE4) }\end{array}$ & 0,840 & Valid \\
\hline $\begin{array}{l}\text { Performance } \\
\text { Expectancy } 5 \text { (PE5) }\end{array}$ & 0,731 & Valid \\
\hline $\begin{array}{l}\text { Performance } \\
\text { Expectancy } 6 \text { (PE6) }\end{array}$ & 0,891 & Valid \\
\hline $\begin{array}{l}\text { Effort Expectancy } 1 \\
\text { (EE1) }\end{array}$ & 0,801 & Valid \\
\hline $\begin{array}{l}\text { Effort Expectancy } 2 \\
\text { (EE2) }\end{array}$ & 0,821 & Valid \\
\hline $\begin{array}{l}\text { Effort Expectancy } 3 \\
\text { (EE3) }\end{array}$ & 0,875 & Valid \\
\hline $\begin{array}{l}\text { Effort Expectancy } 4 \\
\text { (EE4) }\end{array}$ & 0,860 & Valid \\
\hline $\begin{array}{l}\text { Effort Expectancy } 5 \\
\text { (EE5) }\end{array}$ & 0,819 & Valid \\
\hline $\begin{array}{l}\text { Effort Expectancy } 6 \\
\text { (EE6) }\end{array}$ & 0,881 & Valid \\
\hline $\begin{array}{lll}\text { Social } & \text { Influence } & 1 \\
\text { (SI1) } & & \end{array}$ & 0,883 & Valid \\
\hline $\begin{array}{lll}\text { Social } & \text { Influence } & 2 \\
\text { (SI2) } & & \end{array}$ & 0,706 & Valid \\
\hline $\begin{array}{l}\text { Social Influence } 3 \\
\text { (SI3) }\end{array}$ & 0,861 & Valid \\
\hline $\begin{array}{l}\text { Facilating } \\
\text { Conditions } 1 \text { (FC1) }\end{array}$ & 0,829 & Valid \\
\hline
\end{tabular}

\begin{tabular}{|l|l|l|}
\hline $\begin{array}{l}\text { Facilating } \\
\text { Conditions 2 (FC1) }\end{array}$ & 0,826 & Valid \\
\hline $\begin{array}{l}\text { Facilating } \\
\text { Conditions 3 (FC1) }\end{array}$ & 0,719 & Valid \\
\hline $\begin{array}{l}\text { Facilating } \\
\text { Conditions 4 (FC1) }\end{array}$ & 0,721 & Valid \\
\hline $\begin{array}{l}\text { User Satisfaction 1 } \\
\text { (USE1) }\end{array}$ & 0,844 & Valid \\
\hline $\begin{array}{l}\text { User Satisfaction 2 } \\
\text { (USE2) }\end{array}$ & 0,920 & Valid \\
\hline $\begin{array}{l}\text { User Satisfaction 3 } \\
\text { (USE3) }\end{array}$ & 0,855 & Valid \\
\hline $\begin{array}{l}\text { Intention to Use 1 } \\
\text { (ITU1) }\end{array}$ & 0,900 & Valid \\
\hline $\begin{array}{l}\text { Intention to Use 2 } \\
\text { (ITU2) }\end{array}$ & 0,902 & Valid \\
\hline $\begin{array}{l}\text { Intention to Use 3 } \\
\text { (ITU3) }\end{array}$ & 0,880 & Valid \\
\hline Intention to Use 4 & 0,870 & Valid \\
\hline (ITU) & & \\
\hline
\end{tabular}

Selain nilai loading factor, validitas konvergen juga dapat dilihat dari nilai Average Variance Extracted (AVE). Model yang baik memiliki nilai AVE untuk setiap konstruk lebih dari 0,5 seperti yang ditunjukkan pada Tabel 3 (Hasanah et al., 2019). Pada penelitian ini nilai AVE untuk masing-masing konstruk di atas 0,5 , sehingga tidak terdapat masalah validitas konvergen pada model yang diuji. Kemudian bandingkan nilai square root of average variance extracted (akar AVE) setiap konstruk dengan korelasi antara konstruk tersebut terhadap konstruk lainnya dalam model. Menurut Chin (1998), jika nilai akar $A V E$ suatu konstruk lebih besar dibandingkan dengan nilai korelasi konstruk terhadap konstruk lainnya maka dapat disimpulkan konstruk tersebut memiliki nilai validitas diskriminan yang baik dan begitu juga sebaliknya (Chin, 1998). Tabel 4 memperlihatkan bahwa tidak ada masalah dengan validitas diskriminan pada model penelitian ini. 
Tabel 3. Nilai AVE

\begin{tabular}{|l|l|l|}
\hline Konstruk & AVE & Kesimpulan \\
\hline Performance Expectancy & 0,680 & Valid \\
\hline Effort Expectancy & 0,711 & Valid \\
\hline Social Influence & 0,673 & Valid \\
\hline Facilitating Conditions & 0,602 & Valid \\
\hline User Satisfaction & 0,763 & Valid \\
\hline Intention to Use & 0,789 & Valid \\
\hline
\end{tabular}

Tabel 4. Korelasi antar konstruk

\begin{tabular}{|c|c|c|c|c|c|c|}
\hline & PE & EE & SI & FC & USE & ITU \\
\hline PE & $\mathbf{0 , 8 2 8}$ & & & & & \\
\hline EE & 0,711 & $\mathbf{0 , 8 4 3}$ & & & & \\
\hline SI & 0,678 & 0,744 & $\mathbf{0 , 8 2 0}$ & & & \\
\hline FC & 0,641 & 0,754 & 0,680 & $\mathbf{0 , 7 6 6}$ & & \\
\hline USE & 0,678 & 0,802 & 0,635 & 0,656 & $\mathbf{0 , 8 7 4}$ & \\
\hline ITU & 0,708 & 0,713 & 0,677 & 0,596 & 0,779 & $\mathbf{0 , 8 8 8}$ \\
\hline
\end{tabular}

Selanjutnya dilakukan uji reliabilitas dilakukan untuk menguji konsistensi jawaban dari responden. Uji reliabilitas dilakukan dengan menggunakan indikator Composite Reliability dan Cronbach's Alpha. Tabel 5 menunjukkan bahwa semua konstruk memiliki Composite Reliability (CR) dan Cronbach Alpha (CA) berkisar antara 0,783 dan 0,937. Dapat disimpulkan bahwa kelima skala memiliki konsistensi internal yang dapat diterima berdasarkan nilai threshold 0,70 dari Nunnally (1978) (Altinay et al., 2013). Tabel 5 juga menunjukkan bahwa semua faktor memiliki Composite Reliability minimal 0,80, yang lebih tinggi dari nilai ambang 0,70 (Altinay et al., 2013). Dapat disimpulkan bahwa tidak ada masalah dengan reliabilitas dalam model.
Tabel 5. Nilai CR dan CA

\begin{tabular}{|l|l|l|}
\hline Konstruk & $\begin{array}{l}\text { Composite } \\
\text { Reliability }\end{array}$ & $\begin{array}{l}\text { Cronbach's } \\
\text { Alpha }\end{array}$ \\
\hline $\begin{array}{l}\text { Performance } \\
\text { Expectancy }\end{array}$ & 0,929 & 0,907 \\
\hline $\begin{array}{l}\text { Effort } \\
\text { Expectancy }\end{array}$ & 0,937 & 0,919 \\
\hline Social Influence & 0,860 & 0,757 \\
\hline $\begin{array}{l}\text { Facilitating } \\
\text { Conditions }\end{array}$ & 0,857 & 0,783 \\
\hline User Satisfaction & 0,906 & 0,844 \\
\hline Intention to Use & 0,937 & 0,911 \\
\hline
\end{tabular}

\section{Analisis Inner Model}

Tahap ini dilakukan setelah evaluasi model pengukuran berhasil dijalankan hingga menunjukkan hasil yang valid dan reliabel pada keseluruhan indikator penelitian. Diagram jalur yang telah valid kita run kembali menggunakan metode bootstrapping. Pada metode bootstrapping terdapat pilihan pengisian jumlah resampling. Henseler et al., (2009) dan Hair et al., (2011) merekomendasikan untuk menggunakan jumlah resampling data sebesar 5000 (Jörg et al., 2009). Pada penelitian ini digunakan 100 sampel dengan 5000 resampling data. Setelah diagram jalur di-run menggunakan 5000 data resampling, maka diperoleh hasil yang dapat dilihat pada Gambar 3 sebagai berikut: 


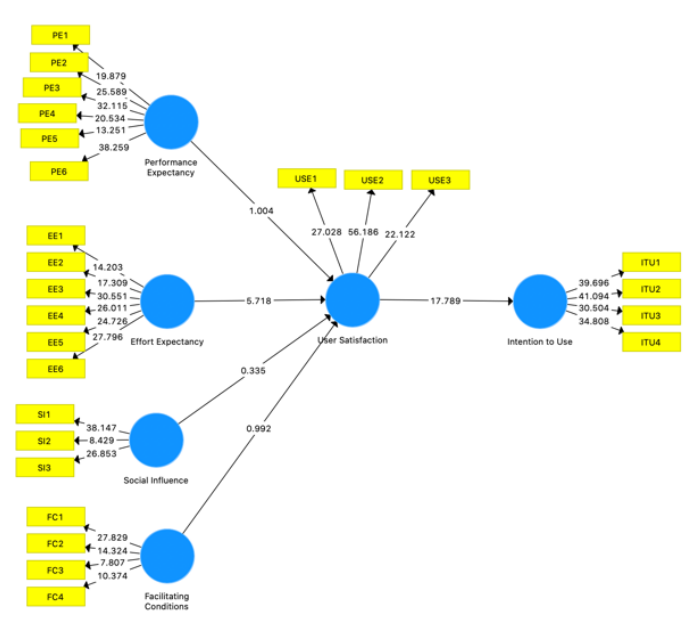

\section{Gambar 3. Hasil Eksekusi Bootstrapping}

Evaluasi model struktural dilakukan berdasarkan nilai dari $R$-Square $\left(R^{2}\right)$, dan predictive relevance $\left(Q^{2}\right)$. Nilai $R$-Square pada model ini adalah ITU 0,607 dan USE 0,657 yang berarti moderat menurut Chin (1998). Selanjutnya nilai predictive relevance ITU 0,468 dan USE 0,480 yang berarti memenuhi syarat menurut Jörg et al. (2009).

\section{Pengujian Hipotesis}

Pengujian hipotesis penelitian diukur dengan menilai Path Coefficient (Mean, STDEV, T-Values) pada kolom T-statistik. Pada tahap pengujian hipotesis, penulis menggunakan tingkat signifikansi $5 \%$, sehingga $t$-value yang digunakan sebagai standar yaitu > 1,97 (two tailed). Terlebih dahulu penulis menjalankan prosedur bootstrapping dalam SmartPLS 3.2.4. Setelah bootstrapping berhasil dijalankan, hasil output dari T-statistik yang menujukkan signifikansi variabel terlihat pada Tabel 6:

Tabel 6. Pengujian Hipotesis

\begin{tabular}{|l|l|l|l|}
\hline Hipotesis & $\begin{array}{l}\text { Path } \\
\text { coefficient }\end{array}$ & T-Statistics & Keterangan \\
\hline $\begin{array}{l}\text { PE } \\
\text { USE }\end{array}$ & 0,316 & 1,004 & $\begin{array}{l}\text { Hipotesis } \\
\text { Ditolak }\end{array}$ \\
\hline $\begin{array}{l}\text { EE } \\
\text { USE }\end{array}$ & 0,000 & 5,718 & $\begin{array}{l}\text { Hipotesis } \\
\text { Diterima }\end{array}$ \\
\hline $\begin{array}{l}\text { SI } \\
\text { USE }\end{array}$ & 0,738 & 0,335 & $\begin{array}{l}\text { Hipotesis } \\
\text { Ditolak }\end{array}$ \\
\hline $\begin{array}{l}\text { FC } \\
\text { USE }\end{array}$ & 0,322 & 0,992 & $\begin{array}{l}\text { Hipotesis } \\
\text { Ditolak }\end{array}$ \\
\hline
\end{tabular}

\begin{tabular}{|l|l|l|l|}
\hline $\begin{array}{l}\text { USE } \\
\text { ITU }\end{array}$ & 0,000 & 17,789 & $\begin{array}{l}\text { Hipotesis } \\
\text { Diterima }\end{array}$ \\
\hline
\end{tabular}

Berdasarkan hasil pengukuran signifikansi pada Tabel 6, dapat dilihat hipotesis mana saja yang memenuhi persyaratan nilai signifikansi yang telah ditentukan. Hipotesis yang memenuhi nilai signifikansi maka hipotesis tersebut akan diterima. Sebaliknya, jika tidak memenuhi nilai signifikansi maka hipotesis tersebut ditolak. Hasil tersebut menunjukkan bahwa faktor-faktor yang mempengaruhi user satisfaction adalah effort expectation. Selain itu, hasil penelitian ini juga menunjukkan bahwa user satisfaction mempengaruhi intention to use. Hipotesis yang tidak diterima adalah performance expectancy, social influence, facilitating conditions. Hal ini menunjukkan bahwa faktor-faktor tersebut kurang mempengaruhi user satisfaction pada evaluasi penerimaan pengguna LMS.

\section{KESIMPULAN}

Penelitian ini bertujuan untuk menganalisis faktor-faktor yang mempengaruhi tingkat kepuasan dengan mengadopsi model UTAUT (Unified Theory of Acceptance and Use of Technology) dan melihat pengaruh kepuasaan pengguna dengan berniat untuk terus menggunakan suatu teknologi baru (e-learning). Penelitian ini mengidentifikasi effort expectancy mempengaruhi user satisfaction. Selain itu penelitian ini juga mengidentifikasi bahwa factor user satisfaction berpengaruh pada intention to use.

\section{REFERENSI}

Altinay, L., Brookes, M., Madanoglu, M., \& Aktas, G. (2013). Franchisees' trust in and satisfaction with franchise partnerships. Journal of Business Research, 67. https://doi.org/10.1016/j.jbusres.2013.11. 034

Chan, F., Thong, J., Venkatesh, V., Brown, S., Hu, P., \& Tam, K. (2010). Modeling Citizen Satisfaction with Mandatory Adoption of an E-Government Technology. Journal of the Association 
for Information Systems, 11, 519-549. https://doi.org/10.17705/1jais.00239

Chin, W. W. (1998). The partial least squares approach to structural equation modelling. In Marcoulides G. A. (Ed.). Modern Methods for Business Research, 295(2), 295-336.

Cho, V., \& Ngai, E. W. T. (2014). A theoretical framework of the influence of mobility in continued usage intention of smart mobile device.

Hasanah, R. L., Wati, F. F., \& Riana, D. (2019). TAM Analysis on The Factors Affecting Admission of Students for Ruangguru Application. Jurnal Sistem Informasi. https://doi.org/10.21609/jsi.v15i2.778

Jörg, H., M., R. C., \& R., S. R. (2009). The use of partial least squares path modeling in international marketing. In R. R. Sinkovics \& P. N. Ghauri (Eds.), New Challenges to International Marketing (Vol. 20, pp. 277-319). Emerald Group Publishing Limited. https://doi.org/10.1108/S14747979(2009)0000020014

Lee, Y.-H., Hsiao, C., \& Hadi, S. (2012). Enhancing e-learning Acceptance: An Empirical Examination on individual and system characteristics. Academy of Management Proceedings, 2012(1), 15828. https://doi.org/10.5465/ambpp.2012.1582 8abstract

Mohamed Ali, W. G. (2016). Nursing Students' Readiness for e-Learning Experience. Gynecology \& Obstetrics, 6(6). https://doi.org/10.4172/21610932.1000388

Ramayasa, I. P. (2015). Evaluation Model of Success and Acceptance of E-Learning. Journal of Theoretical and Applied Information Technology, 3182(3), 462469.

http://www.jatit.org/volumes/Vol82No3/ 16Vol82No3.pdf

Sedana, I. G. N., \& Wijaya, S. W. (2012). Penerapan Model Utaut Untuk Memahami Penerimaan Dan Penggunaan Learning Management System Studi Kasus: Experential E-Learning of Sanata Dharma University. Jurnal Sistem Informasi, $\quad 5(2), \quad 114$. https://doi.org/10.21609/jsi.v5i2.271
Talebian, S., Mohammadi, H. M., \& Rezvanfar, A. (2014). Information and Communication Technology (ICT) in Higher Education: Advantages, Disadvantages, Conveniences and Limitations of Applying E-learning to Agricultural Students in Iran. Procedia - Social and Behavioral Sciences, 152, 300-305. https://doi.org/10.1016/j.sbspro.2014. 09.199

Venkatesh, V., Morris, M., Davis, G., \& Davis, F. (2003). User Acceptance of Information Technology: Toward a Unified View. MIS Quarterly, 27, 425-478. https://doi.org/10.2307/30036540 